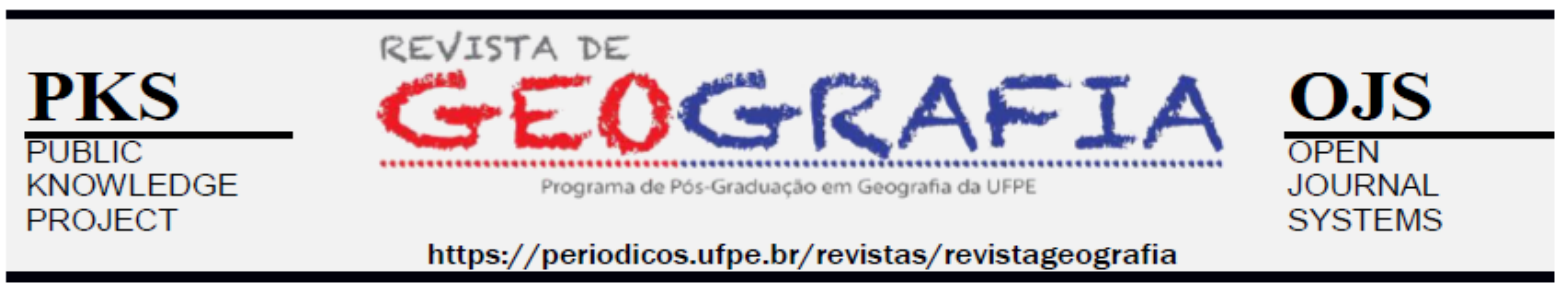

\title{
A ABORDAGEM DE GÊNERO E SEXUALIDADE POR DOCENTES DE GEOGRAFIA NA EDUCAÇÃO BÁSICA EM CURITIBA (PARANÁ)
}

\author{
Murilo Noli da Fonseca ${ }^{1}$, Daiane Nazário ${ }^{2}$ \\ ${ }^{I}$ Pontifícia Universidade Católica do Paraná. E-mail: murilonoli@gmail.com .ORCID: http://orcid.org/0000- \\ 0002-0718-3087 \\ ${ }^{2}$ Colégio Imaculada Conceição. E-mail: daiane.nazario94@gmail.com. ORCID: https://orcid.org/0000-0003- \\ 1656-7055
}

Artigo recebido em 05/07/2021 e aceito em 29/07/2021

\begin{abstract}
RESUMO
A geografia historicamente não é uma disciplina que trabalha com questões de gênero e sexualidade no ambiente escolar ou acadêmico. A inserção desses temas nos campos de estudos da geografia principalmente no Brasil é recente. Sendo assim, o presente trabalho teve como objetivo principal investigar com base em questionários enviados por e-mail e entrevistas semiestruturadas individuais qual é o posicionamento dos professores/as de geografia em relação a essas temáticas e como a ausência ou presença dessas discussões na sua formação inicial ou continuada interfere nas suas práticas pedagógicas. Dessa maneira, notou-se que a formação dos/das docentes se mostrou incompleta em relação a presença desses temas o que resulta na ausência da abordagem em sala de aula.
\end{abstract}

Palavras-chave: Diversidade Sexual; Geografia; Escola; Homossexualidade; Gênero.

\section{THE APPROACH OF GENDER AND SEXUALITY BY GEOGRAPHY TEACHERS IN BASIC EDUCATION IN CURITIBA (PARANÁ)}

\begin{abstract}
Geography is historically not a discipline that works with issues of gender and sexuality in the school or academic environment. The insertion of these themes in the fields of geography studies mainly in Brazil is recent. Thus, the main objective of this study was to investigate based on questionnaires sent by e-mail and individual semi-structured interviews what is the position of geography teachers in relation to these themes and how the absence or presence of these discussions in their initial or continued education interferes in their pedagogical practices. Thus, it was noted that the education of teachers was incomplete in relation to the presence of these themes, which results in the absence of the classroom approach.
\end{abstract}

Keywords: Sexual Diversity; Geography; School; Homosexuality; Gende. 


\section{INTRODUÇÃO}

A escola é palco de inúmeros acontecimentos, pois é o principal espaço de convívio social e a realização de momentos significativos na vida de quem a frequenta. No entanto, acontecem situações que não são confortáveis para determinados adolescentes, que são tratados de forma hostil devido ao preconceito em relação a sua sexualidade ou a sua identificação de gênero. A partir dessas situações, é possível refletir sobre o papel da escola diante disto e como professores/as podem interferir. Entretanto, os profissionais de educação, muitas vezes, não se sentem preparadas/os para agir, nesses momentos, já que não há conhecimento relacionado aos temas, que raramente aparecem na graduação ou em formações continuadas.

Apesar de serem temas passíveis de aparecer não somente nas aulas de Geografia, mas em outras disciplinas, como Biologia e Sociologia, o gênero e a sexualidade são saberes muitas vezes ignorados pelos profissionais de educação. Os motivos que levam a isso são variados. $\mathrm{Na}$ Geografia, o estudo desses temas tem um número reduzido de pesquisadores e as produções sistemáticas são poucas (SILVA, 2007). No Estado do Paraná, por exemplo, as Diretrizes Curriculares referentes a disciplina de Geografia não trazem nenhuma menção ao ensino de gênero ou sexualidade, o que dificulta ainda mais a abordagem dos (as) professores (as) em sala de aula, visto que não há uma diretriz que norteie os professores em sala de aula.

Logo, o presente artigo tem como proposta analisar a importância de se trabalhar questões de gênero e sexualidade nas aulas de Geografia, contribuindo para a formação de crianças, adolescentes, jovens e pessoas adultas em relação às diferenças. Além do mais, procura compreender e explicar como algumas professoras e professores (em diversos estágios da carreira docente) da rede pública estadual de ensino de Curitiba (Paraná) percebem a relação entre estes temas e à docência em Geografia. Busca-se ainda compreender como elas/es analisam a sua formação no que se refere a presença ou ausência desses temas em suas aulas.

\section{REVISÃO DE LITERATURA}

A sexualidade é aqui interpretada de acordo com a visão de Michael Foucault (19261984) que, no primeiro volume da sua obra História da Sexualidade - a vontade de saber, demonstra a constituição da sexualidade no ocidente como um dispositivo definido por uma rede heterogênea de poderes. $\mathrm{O}$ autor demonstra como a sexualidade passou a ser alvo de controle por uma série de poderes difusos, que exercem sua força sobre as pessoas ditando 
regras, comportamentos, práticas, entre outros. A sexualidade, então, passa a ser regulada de acordo com um dispositivo.

Foi a partir do estabelecimento de uma rede de saber-poder sobre o corpo e o sexo que a normatização e normalização dos comportamentos sexuais foram produzidas. Estes processos resultaram em um controle das práticas sexuais da população no século XIX. Ainda nos dias de hoje é possível perceber a existência de uma normatização da sexualidade e dos modos de vida das pessoas. Pois, todos e todas estão enredadas/os por uma heteronormatividade vigente. Quando os papéis de gênero são estabelecidos, a sexualidade também acaba sendo direcionada. Dessa maneira, espera-se que meninas gostem de meninos, cuidem de suas bonecas e brinquem de cozinhar e cuidar da casa. O mesmo acontece com os meninos, que são incentivados desde cedo a brincar com carrinhos e a gostarem de meninas, que são mais frágeis e precisam de um homem que as proteja. Essa ideia foi inventada no final do século XIX, onde serão homens, médicos e também filósofos, moralistas e pensadores (das grandes nações da Europa) que vão fazer as mais importantes "descobertas" e definições sobre os corpos de homens e mulheres.

A ideia de inserir sexualidade e gênero no contexto escolar não é atual. No Brasil, antes do surgimento dos Parâmetros Nacionais Curriculares, em 1998, essas temáticas já eram discutidas, numa concepção própria daquele momento histórico. A concepção que permeava essas ideias era de cunho higienista e eugênico (CÉSAR, 2009). Ela buscava prevenir as relações de sexuais, de tal forma que a masturbação e os outros desejos sexuais fossem escondidos das/dos adolescentes. A década de 1960 foi marcada por mudanças que também estavam acontecendo no âmbito da pedagogia, a educação sexual acompanhou essas mudanças. Com a ditadura militar essas questões deixam de ser levantadas no ambiente escolar. Após o fim desse período, na década de 1980 e 1990 o mundo se depara com a epidemia de AIDS/HIV e é nessa perspectiva que a educação sexual retorna às salas de aula.

Foi somente na década de 1990 que essas questões são adicionadas aos Parâmetros Curriculares Nacionais. A educação sexual então, passou a ser quase sempre discutida no âmbito da prevenção. A sexualidade nas escolas muitas vezes foi trabalhada de um modo que criasse vergonha e em alguns casos traumas aos/as estudantes, pois era trabalhada da seguinte maneira.

Após estudar os aparelhos circulatório, respiratório, digestivo, no 4 final do ano letivo, a professora de ciências, um pouco constrangida anunciava o estudo dos "aparelhos reprodutores", masculino e feminino. Nesse momento, se aproveitava para mostrar 
imagens em grandes projeções ou cartazes dos órgãos genitais deformados por enfermidades "venéreas" (CÉSAR, 2008, p.3-4).

Ao abordar a sexualidade expondo principalmente as doenças venéreas, muitos professores e professoras criavam nos/nas estudantes traumas ou nojo. Essa forma de trabalhar essas questões está muito ligada à prevenção ao ato sexual, ideia essa que permeou a educação sexual nas escolas por muitos anos e em alguns casos, existe até os dias de hoje. Na segunda metade da década de 1990, a criação dos Parâmetros Curriculares Nacionais trouxe consigo a concepção de que o tema orientação sexual deve aparecer nas escolas. Eles indicam o que deve ser trabalhado, mas a escolha sobre abordar ou não cabe a cada escola e a cada professor.

A Geografia, no entanto, não se aprofundou nos estudos relacionados às questões de gênero e sexualidade. As produções científicas nessa área são recentes, da década de 1990. Apesar da produção ser recente e de existirem relativamente poucos trabalhos na área, há um gradual aumento nas produções relacionadas a esses temas se comparadas com as décadas anteriores.

\section{METODOLOGIA}

Os dados obtidos para a presente análise foram coletados através de dois instrumentos: entrevista estruturada e questionário aberto. Os questionários foram enviados via e-mail para oito profissionais de educação escolhidos de forma aleatória e as entrevistas foram realizadas pessoalmente. As perguntas dos questionários foram as mesmas das entrevistas, o que possibilitou entender qual dos instrumentos de pesquisa foi mais eficaz para o trabalho. As perguntas foram divididas em eixos:

- O primeiro contém três perguntas de caráter opinativo sobre a importância de gênero e sexualidade, as abordagens sobre ele e a contribuição da Geografia;

- $\quad$ O segundo possui duas perguntas que investigam a formação inicial e continuada dos professores/as;

- $\quad$ O terceiro questiona a prática dos/das professores/as e se em algum momento de sua docência já discutiram esses temas em sala de aula; e

- $\quad$ O quarto e último possui uma pergunta sobre os livros didáticos de geografia e a sua contribuição ou não para a discussão desses temas.

Com base nisso, os (as) entrevistados (as) foram escolhidos de acordo com o tempo de docência. Foi escolhido alguém que está no início da carreira (5 meses), meio (16 anos) e final (27 anos). A escolha dos períodos se deu para compreender se o tempo de docência interfere na concepção dos (as) entrevistados (as). 
A partir das respostas obtidas foi possível criar categorias de análises para as respostas, assim, agrupando-as respostas similares

\section{RESULTADOS}

Para compreender como profissionais de educação concebem a presença desses temas em sala de aula foram feitas três entrevistas pessoalmente com esses profissionais, que se encontram lotados na rede estadual de ensino, em Curitiba. Além do mais, foram aplicados oito questionários para profissionais da rede pública de ensino e privada, os quais também tem diferentes tempos de carreira. Para preservar a identidade de cada uma/um, serão utilizadas as iniciais dos/das entrevistados/entrevistadas.

As respostas à primeira pergunta: "Na sua opinião temas como gênero, sexualidade e diversidade sexual devem ser discutidos na escola? Por quê?" foram unânimes. Todos responderam que esses temas devem aparecer em sala de aula. Sobre essa importância, seis profissionais de educação argumentaram que esses temas devem ser discutidos na escola pela importância social, de convivência e de formação das (os) estudantes que eles podem proporcionar.

\footnotetext{
Porque acredito que é na escola que a gente tem que desenvolver o nosso esse nosso lado justamente porque é o centro de convivência. Porque se justamente no centro convivência dos alunos eles não tiverem esse conhecimento e discussão, e em casa dificilmente eles vão ter (PROFESSORA A.B., 2016).
}

Outros dois profissionais interpretam que esses temas são de suma importância no processo de ensino-aprendizagem, pois podem contribuir para uma sociedade igualitária para as pessoas, como se pode perceber pela resposta:

Para promover a igualdade e o respeito na comunidade escolar e, consequentemente, na sociedade (PROFESSORA A.N., 2016).

Duas respostas afirmam que esses temas podem ser mais discutidos pois são mais atuais e fazem parte desse momento da nossa sociedade. Nesse sentido:

Tenho vontade de responder como o primeiro ministro canadense e dizer: porque estamos em 2016. Na verdade, o que quero dizer é que de maneira geral as questões 
de gênero e sexualidade permeiam vários ambientes e a discussão na escola está atrasada, o que é uma pena, pois poderíamos ajudar os estudantes que se encontram em dilemas (PROFESSORA R. D., 2016).

Outra resposta afirmou que discutindo esses temas a discriminação é evidenciada, o que ajuda no combate a situações vexatórias para as/os estudantes.

Devem ser discutidos, pois evidenciam situações de constrangimento e discriminação. Contudo, o docente deve tomar cuidado para conduzir o temário e não reproduzir preconceitos da sociedade heteronormativa, elitista, branca e machista (PROFESSOR R. B., 2016).

As respostas dessa pergunta evidenciam que as (os) profissionais de educação, de maneira geral, estão bem esclarecidas (os) quanto a importância desses temas na escola e que a inserção de tais pode, de alguma forma, contribuir para que a sociedade seja justa para todas/os, diferindo apenas no que se refere ao motivo da importância. Sobre isso, enquanto profissionais de educação que percebem as desigualdades existentes, dentro e fora do espaço da escola. Logo,

Se admitimos que a escola não apenas transmite conhecimentos, nem mesmo apenas os produz, mas que ela também fabrica sujeitos, produz identidades étnicas, de gênero, de classe; se reconhecemos que essas identidades estão sendo produzidas através de relações de desigualdade; se admitimos que a escola está intrinsecamente comprometida com a manutenção de uma sociedade dividida e que faz cotidianamente, com nossa participação ou omissão, se acreditamos que a prática escolar é historicamente contingente e que é prática política, isto é, que se transforma e pode ser subvertida, e, por fim, se não nos sentimos conformes com essas divisões sociais, então, certamente, encontramos justificativas não apenas para observar, mas, especialmente, para tentar interferir na continuidade dessas desigualdades (LOURO, 2007, p. 85-86).

A segunda pergunta: "Se você acha que são temas que deveriam estar na escola, como deveriam ser essas abordagens?" dividiu a opinião das (os) profissionais de educação. O primeiro grupo (oito) acredita que a melhor abordagem para esses temas é com atividades diferenciadas (oficinas, palestras, rodas de conversa) como é explicitado na resposta: 
$\mathrm{Na}$ escola como um todo por meio de palestras, trabalhos em grupos, rodas de conversa e outros (PROFESSOR P.F., 2016).

Um segundo grupo de profissionais (dois) acredita que esses temas devem ser trabalhados de forma transversal, assim, não é somente responsabilidade da geografia trabalhar com eles e, sim, de todas as disciplinas escolares. A resposta do professor O.P. evidencia essa ideia:

Tal como a educação ambiental, acredito que esses temas se caracterizam como temas transversais, ou seja, não podem ser discutidos por uma área do saber especifica, devendo estar presentes em todos os componentes curriculares da formação discente assim como sua discussão deve ser incentivada fora da sala de aula, sempre cultivando o respeito mútuo (PROFESSOR O.P., 2016).

Um terceiro tipo de resposta diz que esses temas podem aparecer em qualquer conteúdo da geografia, basta a (o) profissional saber fazer um paralelo com a questão.

Todos os conteúdos da geografia são possíveis de serem abordados junto com esses temas. Na geografia sempre trago essas questões, principalmente da mulher, quando trabalho a demografia, população economicamente ativa dos países, o papel da mulher nas diferentes sociedades e países, como a mulher é importante na agricultura familiar, enfim, os índices relacionados à mulher (PROFESSORA S.B., 2016).

Essa resposta mostra que dependendo do grau de aproximação que a (o) docente tem com esses temas, eles poderão ser trabalhados dentro de diversos conteúdos da geografia. A forma como essas temáticas deveriam ser trabalhadas em sala de aula depende de várias questões como: a faixa etária de estudantes, os recursos disponíveis na escola, o envolvimento da comunidade escolar com essas questões, o compromisso da/o professoras $/ \mathrm{r}$ com o enfrentamento das violências, dentre outros fatores. Sobre a melhor maneira de abordagem:

Para a educação não há "receitas prontas", a realidade desvelará questões latentes e caberá aos docentes a definição do método que melhor se adapta ao assunto e à realidade de seu trabalho. Temas como gênero e sexualidade não pretendem e tampouco devem substituir os conteúdos "tradicionais" das disciplinas que compõe o currículo escolar. Uma das possibilidades consiste no tratamento como tema transversal, forma que possibilita a inserção dessas questões sociais presentes no diaa-dia do estudante e em debate na sociedade, sem deixar "de lado" outros assuntos tão 
importantes quanto. Muitas dessas questões revelam preocupações da sociedade, exigem análise crítica e posicionamento do grupo discente, mas podem ser trabalhadas de forma articulada com outros temas já tratados nas disciplinas escolares (FERREIRA; DA LUZ, 2007, p.43).

É possível compreender pela fala das autoras que inserir esses temas de forma transversal pode ser uma boa alternativa, pois, assim, muitos assuntos podem ser trabalhos em conjunto inclusive com disciplinas já trabalhadas no currículo escolar. A terceira pergunta: "Você acha que a Geografia tem alguma contribuição com a discussão desses temas?” também obteve respostas unânimes. Todas (os) acreditam que a Geografia pode contribuir com essas discussões, pois é uma ciência que também estuda a sociedade. Logo, seriam assuntos passíveis de uma investigação geográfica. A resposta da professora T. B. demonstra isso:

Acredito que sim, pois uma ciência que se relaciona com as atividades sociais no espaço abrange os problemas que envolvem também as relações sociais e dentre elas esses assuntos (PROFESSORA T.B., 2016).

Essa resposta mostra que todas/os percebem que a geografia de alguma forma tem grandes possibilidades de trabalhar com estes temas pois é uma ciência que também estuda a sociedade. Silva (2009) faz uma reflexão sobre isso e ainda conclui que essas questões deveriam ser algo de grande interesse da geografia:

O alcance da centralidade da perspectiva de gênero nas ciências sociais no Brasil e a contraditória impermeabilidade da ciência geográfica fica a ela configuram uma situação, no mínimo, curiosa, considerando que a geografia é uma ciência da sociedade. Qualquer ciência que tenha como foco de análise as relações humanas deve ter em conta que a humanidade não é uniforme e que a diferença entre homens e mulheres é uma das principais categorias de análise. Além disso, as relações de gênero permeiam todas as sociedades, apesar das diferenças espaciais e temporais (SILVA, 2009, p.60).

A quarta pergunta: "Durante a sua formação acadêmica teve algum contato com esses temas?" investigava se os (as) docentes tiveram contato com estes temas em algum momento da graduação. Apenas dois responderam que tiveram contato, sendo que um relata: "Que eu me recorde, de forma direta esses temas não foram abordados. Mas de forma indireta sim" 
(PROFESSOR P.T.,2016), enquanto o outro relatou que: "Sim, através de discussões em sala" (PROFESSOR P.F., 2016). Todos (as) os (as) outras (os) responderam que não tiveram ou tiveram pouco. Nota-se que há uma ausência de disciplinas ou atividades que envolvam essa temática, o que, de certa forma, também influencia na prática docente. É possível refletir sobre a importância de serem inseridas, nos currículos de cursos superiores, disciplinas que ofereçam aparato aos futuros profissionais. Com base nisso,

Destaca-se a importância dessa formação, pois, mudanças nas concepções e práticas escolares dependem, sobretudo de preparo e sensibilização docente. A inclusão de temas como gênero e sexualidade nos cursos regulares e de educação continuada oferecerá base teórica e metodológica para que o docente tenha segurança para apresentar e debater essas questões que, por sua relevância, não podem ser tratadas de qualquer maneira. Esse tipo de ação também possibilitará que os educadores enfrentem situações que aparecem no seu cotidiano e que exigem respostas educacionais: discriminações de gênero, homofobia, sexismo, gravidez na adolescência, doenças sexualmente transmissíveis, aborto, etc (FERREIRA; DA LUZ, 2007, p.42).

A pergunta número cinco: "Durante a sua atuação como docente participou de alguma formação em ação ou formação continuada para fundamentar o trabalho pedagógico com estas questões? Se sim: Qual? Você poderia descrever como foi? Se não: Você considera importante a oferta destas formações pela mantenedora do sistema de ensino no qual você trabalha? Por quê?" é a pergunta mais extensa. As (os) profissionais responderam que concordam que é importante que as instituições das quais trabalham ofereçam formações relacionadas aos temas. Sobre a participação em formações, oito docentes não tiveram nenhum tipo ou insuficiente. Apenas três profissionais participaram de formações continuadas, todas elas oferecidas pela SEED - Secretaria de Estado de Educação do Paraná. É possível identificar a descrição dessas atividades na resposta:

Sim, a partir de 2009 quando participei com o Núcleo de Educação da Região Metropolitana Sul que na época possuía um núcleo chamado Núcleo de Gênero e Diversidade Sexual, esse núcleo era da Secretaria de Educação do Estado do Paraná coordenado pela Professora Dayana Brunetto, era uma demanda da SEED para o Núcleo e eram fornecidos vários cursos, mini cursos, oficinas, oficinas online, palestras e discussões. Era uma formação constante. Essa foi uma época em que 
surgiram várias conquistas para as trans que eram inviabilizadas, elas passaram a ter o direito que terem os seus nomes sociais na escola. Foi um período de grande avanço nessas discussões que deixou um legado muito grande aos professores que participaram mas infelizmente não atingiu a todos, principalmente depois da troca de governo, que todas essas atividades foram encerradas (PROFESSORA S.B., 2016).

As falas das (os) docentes que tiveram formações continuadas se referem ao Departamento de Diversidade e Núcleo de Gênero e Diversidade Sexual, que realizou diversas atividades sobre o tema. Foram momentos de intensas trocas e aprendizados nos quais as/os participantes puderam se aproximar de assuntos que ainda são tratados como excêntricos em nossa sociedade. Ainda sobre a questão da formação continuada, Ferreira; Da Luz (2007) refletem que a inserção dessas questões nas formações de docentes contribuiria para que a nossa sociedade deixasse de ser tão desigual. Nas palavras das autoras:

A inclusão de temáticas de gênero e sexualidade em cursos de formação docente contribuiria para essa problematização e para uma análise crítica do que é reproduzido pela instituição escolar. A formação cidadã não pode deixar de considerar que se vive numa sociedade desigual, e que tais questões são fatores que contribuem para a construção das desigualdades sociais. Esse reconhecimento é essencial para a intervenção e a promoção de mudanças sociais (FERREIRA; DA LUZ, 2007, p. 44).

A sexta pergunta "Durante a sua prática docente em algum momento você abordou essas temáticas em sala de aula?” investiga se a prática das/dos professoras/es já contemplou essas questões em algum momento da carreira. Quatro docentes responderam negativamente à pergunta. Na primeira pergunta, todas (os) responderam que acham que essas questões deveriam ser discutidas na escola. Isso mostra que, mesmo afirmando a importância, a abordagem efetiva do tema depende de fatores como: preparação da/o docente e apoio da instituição escolar. Este último fator pode ser notado na resposta do seguinte profissional:

De maneira indireta em conversas informais sim, pois esse tipo de temática não está inserida na grade e não a possibilidade de tratar essa temática dentro dos conteúdos diários, até mesmo porque pode sofrer algum tipo de pressão negativa da instituição ou dos pais de alguns alunos (PROFESSOR P.T., 2016). 
O segundo tipo de respostas que surgiu foi que três docentes dialogam sobre esses temas quando há alguma situação de preconceito em sala de aula:

\begin{abstract}
Sim, muitas vezes e me esforço para abordar esses temas quando percebo que ocorre na sala de aula algum tipo de preconceito, quanto identidade de gênero e/ou orientação sexual. Como sou professor, os alunos respeitam a minha opinião e escutam as contribuições dos colegas. Percebo que na maioria das vezes, essas minhas abordagens surti um efeito positivo quanto o combate à discriminação e aos casos de preconceito (PROFESSOR R.B., 2016).
\end{abstract}

Essa postura demonstra que esses docentes têm uma preocupação com a relação entre as (os) estudantes e interferem quando acham necessário. Tal posicionamento é necessário, pois se a (o) profissional não intervir, certamente, estudantes poderão se sentir feridas (os) com comentários preconceituosos de colegas. Duas respostas que também apareceram referem-se a que as (os) docentes abordam essas questões através de atividades diferenciadas, ou seja, seminários, rodas de conversa e outros:

Através de seminário onde cada grupo sorteou um tema referente aos movimentos sociais, dentre eles o movimento LBGT (PROFESSOR P.F., 2016).

Essas respostas mostram que essas (es) docentes não se aprofundam tanto nas questões a ponto de inseri-las no conteúdo curricular da geografia. Isso pode acontecer por falta de conhecimento de como fazer esse paralelo. Diferente do último grupo de respostas, o outro que surgiu foi de profissionais que inserem essas temáticas tanto em conteúdos programados quanto em situações nas quais necessitam interferir. Essas respostas demonstram um maior envolvimento das (os) professoras (es), tendo em vista que se comprometem a discutir essas temáticas nos seus conteúdos programados. Nesse sentido, a professora S B. relata que:

Sempre que possível desde uma piada que um aluno faz até os conteúdos programados. Existem escolas que são mais resistentes à abordagem desses temas, em outras é mais fácil (PROFESSORA S.B., 2016).

A última pergunta: "Os livros didáticos de Geografia contribuem para a discussão desses temas?” obteve diferentes respostas. Uma pessoa não respondeu. Outras cinco respostas 
afirmam que os livros didáticos de geografia não abordam esses temas. E quatro respostas indicaram que os livros trazem "pouca" abordagem sobre as temáticas. A última resposta encontrada foi:

\author{
Muito pouco. Lucia Marina traz nos seus livros mas pouco. Quando os livros trazem \\ eles trazem apenas dados estatísticos e não um texto de conscientização \\ (PROFESSORA F.I., 2016).
}

Um dos livros citados se referia era da Coleção Fronteiras da Globalização da Editora Ática do ano de 2013. Esse livro traz um capítulo chamado "Desigualdades entre os gêneros e as etnias". A primeira parte do capítulo explica que o mundo é marcado por desigualdades políticas, econômicas e sociais e, que, apesar da evolução da sociedade em vários sentidos, ainda há uma desigualdade entre os gêneros. Nesse capítulo há uma foto da ex-presidente do Brasil Dilma Vana Rousseff, primeira mulher eleita presidenta no país. O texto fala sobre empoderamento da mulher e como ele é fundamental para que a sociedade caminhe para uma igualdade. São trazidos exemplos de mulheres que se destacaram na História.

Outra parte do texto diz que é necessário que existam políticas de equidade entre os gêneros, informa que no Brasil existe a Secretaria de Políticas para Mulheres e o Conselho Nacional dos Direitos da Mulher e, que, a equidade entre os gêneros é uma das metas dos Objetivos do Milênio. Além disso, relata que a ONU (Organização das Nações Unidas) criou em 2011 a ONU Mulheres, organização que visa a igualdade de gênero e o empoderamento das mulheres. O capítulo ainda apresenta o Índice de Desigualdade de Gênero que mostra o quão desigual os países são. Os países que apresentam o valor mais próximos de 1 são os que possuem maior desigualdade entre os gêneros enquanto os que apresentam os valores mais próximos de 0 são aqueles onde há menos desigualdade. As maiores desigualdades entre os gêneros estão nos países africanos e asiáticos, enquanto os melhores índices estão nos países europeus. O texto ainda traz uma escrita complementar que conta o início do movimento feminista com as sufragistas.

A partir da análise desta obra é possível constatar que mesmo que a maioria das (os) profissionais de educação ainda não tenha visto essas questões nos livros didáticos de geografia existem algumas opções de autoras/autores que abordam os temas ajudando na compreensão das/os estudantes e também das/os professoras/es. Para que as/os professoras/es possam trabalhar com essas obras, entretanto, é preciso que estes sejam os livros escolhidos pelas 
instituições escolares. Assim, as/os professoras/es devem se atentar a esses detalhes na hora da escolha

\section{CONCLUSÃO}

Através das respostas obtidas nos questionários e entrevistas foi possível perceber que as (os) profissionais de educação não tiveram nenhum ou pouco contato com essas temáticas, o que também dificulta que abordem essas questões na sua prática docente. Aliada a essa questão, a partir de entrevistas individuais e questionários feitos com essas (es) docentes procura-se descobrir como eles/as percebem a importância da sua formação em relação às questões de gênero e sexualidade e sobre a forma como estas interferem nas suas práticas.

No que se refere à Geografia, parece ficar ainda mais complicado abordar esses temas, pois no ambiente acadêmico, em relação aos outros campos de pesquisa, não há uma grande quantidade de pesquisas relacionadas às questões de gênero e sexualidade. Isso se reflete nas grades curriculares e disciplinas ofertaras na formação inicial dos educadores e educadoras. Essa ausência também está nos livros didáticos ou eles abordam, muitas vezes, de forma inadequada, principalmente, quando retratam as questões das mulheres. No entanto, se as (os) docentes estiverem atentas (os) e preparadas (os) podem usar essa ausência ou imagens carregadas de preconceito a favor do seu trabalho pedagógico, provocando as (os) estudantes a refletirem sobre a sociedade na qual vivemos.

\section{REFERÊNCIAS}

CÉSAR, M.R.A. Gênero, sexualidade e educação: notas para uma epistemologia. Educar em revista. Curitiba, n. 35, set./dez. Editora UFPR. 2009, p. 37-51.

Gênero e sexualidade na escola: produzindo corpos, narrativas

e significados. Florianópolis: Fazendo gênero - Corpo, Violência e Poder, 2008.

FERREIRA, B.; DA LUZ, S.N. Sexualidade e gênero na escola. In: DA LUZ, S.N; CARVAlHO, G.M.; CASAGRANDE, S.L. (Orgs.) Construindo a igualdade na diversidade. Curitiba: Editora UTFPR, 2009. pp. 33-45.

FOUCAULT, M. História da Sexualidade I: a vontade de saber. Rio de Janeiro: Graal, 1984.

LOURO, G.L. Gênero, sexualidade e educação: uma perspectiva pós-estruturalista. Petrópolis: Vozes, 2007. 
SILVA, J.M. Gênero e sexualidade na análise do espaço urbano. Geosul (UFSC), v. 22, p. 117134, 2007.

Ausências e silêncios do discurso geográfico brasileiro: uma crítica feminista geografia eurocêntrica. SILVA, J.M. (Org.). In: Geografias subversivas: discursos sobre espaço, gênero e sexualidades. Ponta Grossa, PR: Toda palavra, 2009.

SILVA, J.M.; SILVA, C.A.P; (Orgs.). Espaço, gênero e poder: conectando fronteiras. Ponta Grossa, PR: Toda palavra, 2011. 